\title{
Normative Influences on Aggression in Urban Elementary School Classrooms ${ }^{1}$
}

\author{
David Henry ${ }^{2}$ and Nancy Guerra
}

University of Illinois at Chicago

\section{Rowell Huesmann}

University of Michigan

\section{Patrick Tolan and Richard VanAcker}

University of Illinois at Chicago

\section{Leonard Eron}

University of Michigan

We report a study aimed at understanding the effects of classroom normative influences on individual aggressive behavior, using samples of 614 and 427 urban elementary school children. Participants were assessed with measures of aggressive behavior and normative beliefs about aggression. We tested hypotheses related to the effects of personal normative beliefs, descriptive classroom norms (the central tendency of classmates' aggressive behavior), injunctive classroom normative beliefs (classmates' beliefs about the acceptability of aggression), and norm salience (student and teacher sanctions against aggression) on longitudinal changes in aggressive behavior and beliefs. Injunctive norms affected individual normative beliefs and aggression, but descriptive norms had no effect on either. In classrooms where students

\footnotetext{
${ }^{1}$ This research was supported in part by Grant No. MH-48034 from the National Institute of Mental Health. The authors thank Sherri Lantinga, Laura Hanish, Sharon Grant, and Henry Sadowski, who, among many others, assisted in data collection and data processing for this project. The authors also gratefully acknowledge the contributions of four anonymous reviewers for their thoughtful comments on the manuscript.

${ }^{2}$ All correspondence should be sent to David Henry, the Institute for Juvenile Research (M/ C 747), University of Illinois at Chicago, 907 S. Wolcott Ave., Chicago, Illinois 60612.
} 
and teachers made norms against aggression salient, aggressive behavior diminished over time. Implications for classroom behavior management and further research are discussed.

KEY WORDS: aggression; children; normative influence; classrooms.

Over the past several decades there has been an increasing emphasis on the role of cognition in the learning and regulation of children's aggressive behavior. One line of research has focused on attributional biases and their relation to aggression in children and adolescents (Dodge, 1986). Another has investigated the role of defective response selection processes (Guerra \& Slaby, 1990; Slaby \& Guerra, 1988), and a third has focused on the role of social schemata, i.e., organized prior knowledge that guides and shapes how information is processed (Crick \& Dodge, 1994; Guerra, Huesmann, \& Hanish, 1994; Huesmann, 1988; Huesmann \& Guerra, 1997). For example, if a child has been provoked and is selecting an appropriate response, it is likely that prior beliefs about the acceptability of various responses will influence his or her decision.

Along these lines, several studies have examined the relation between children's normative beliefs about aggression and their actual behavior. In these studies normative beliefs have been defined as an individual's cognitions about the acceptability or unacceptability of behaviors that regulate corresponding actions (Guerra et al., 1994; Huesmann \& Guerra, 1997). Such beliefs are both situation specific and general. An example of a situation-specific normative belief is "It's okay to hit others if they hit you first." An example of a general belief is "It's okay to hit others." Both situation specific and general beliefs have been found to be significantly related to children's actual aggressive behavior (Huesmann \& Guerra, 1997; Huesmann, Guerra, Miller, \& Zelli, 1992; Huesmann, Guerra, Zelli, \& Miller, 1992). Furthermore, the relation between normative beliefs and behavior appears to vary developmentally. In a longitudinal study of normative beliefs and aggressive behavior among elementary school aged children, Huesmann and Guerra (1997) found that aggressive behavior predicted future normative beliefs for children in the early grades, but by the middle grades this relation reversed itself. Also, as children increase in age, the strength of the longitudinal correlation between earlier normative beliefs and later aggressive behavior increased.

Although previous studies of children's normative beliefs about aggression have been conducted largely in school settings, they generally have not considered how specific school contexts affect normative beliefs and behavior. Classroom influences may be quite important in children's early social development through processes such as social comparison (Levine, 
1983). An understanding of normative influences on children's aggression would probably be enhanced by attending to the influence of salient social contexts such as the classroom.

The purpose of the present study was to examine the relations among individual and classroom normative influences and children's aggression. In addition to an individual's own normative beliefs, three types of classroom influences were investigated: descriptive norms, injunctive norms, and norm salience. Descriptive and injunctive norms were operationalized according to the definition offered by Cialdini, Kallgren, and Reno (1990). Using this definition, descriptive norms refer to norms that describe what most people will do, and injunctive norms refer to norms that characterize what people are expected to do. This is consistent with other distinctions between social norms as descriptors for behavior ("what is") and social norms as directives for behavior ("what ought to be"; Deutsch \& Gerard, 1955). Norm salience was operationalized as the extent to which each classroom made injunctive norms regarding aggression salient by virtue of higher peer rejection and lower peer popularity for aggressive children as well as the frequency of contingent teacher reprimand for aggressive behavior.

Three main hypotheses guided this study. First, we expected that descriptive norms (based on classmates' actual aggressive behavior) and injunctive norms (based on classmates' normative beliefs about aggression) would be significant predictors of change in individual aggressive behavior, while controlling for earlier individual beliefs and aggression. The proposed effects of observed behavior of others are consistent with a substantial body of literature demonstrating the effects of modeling on behavior (see Bandura, 1986, for a review). However, because the majority of classroom time is spent in situations where opportunities for observation of others behaving aggressively are limited, children's verbalizations of beliefs about aggression may be nearly as influential as their actual behavior (Grusec, 1972). Thus, we also expected injunctive norms to be important predictors of behavior.

Second, we expected that these effects would vary with age. Huesmann and Guerra (1997) found that among younger children, aggressive behavior longitudinally predicts change in normative beliefs, whereas among older children, normative beliefs longitudinally predict change in aggressive behavior. Based in part on these findings, we predicted that in the earlier grades descriptive norms would predict aggressive behavior that would predict, in turn, individual normative beliefs. In the older grades we expected that injunctive norms would predict individual normative beliefs that would predict, in turn, aggressive behavior. Thus, for younger children, we expected an indirect effect of classroom descriptive norms on normative beliefs through individual aggression, and for older children, an indirect 
effect of classroom injunctive norms on aggression through individual normative beliefs.

Finally, we predicted that norm salience would also be related to changes in children's aggression. Specifically, we predicted that children would show the smallest increase in aggression over time in classrooms where both peers and teachers disapproved of aggressive behavior. Not only should what children do and say be predictive of aggression, but classroom rewards or sanctions should also exert an influence. This is consistent with the notion that behavior settings develop "deviation countering circuits" that exert influence to make individual behavior conform to the program of the setting (Barker, 1968).

\section{METHOD}

\section{Participants}

Data from two samples were used in this research. Research participants in the exploratory sample were 614 students (315 females and 299 males) from 14 economically disadvantaged public schools taking part in a large, multiwave intervention (for a complete description of school and participant selection procedures, see Guerra, Eron, Huesmann, Tolan, \& Van Acker, 1995). Seven of these schools were located in impoverished areas of a large city, and seven were in impoverished areas of a neighboring, smaller city. For the present study, we chose students in classrooms where permission and all measurements could be obtained for 10 or more children in 1993, for a total of 45 classrooms (average $\bar{n}=13.1$ per class). The sample was comprised of $31.3 \%$ first graders, $28.3 \%$ second graders, and $40.5 \%$ fourth graders. The ethnic composition of the sample was $33.2 \%$ African American, 43.1\% Latino, 21.5\% Anglo, and 1.6\% other ethnic groups. Approximately $62 \%$ of the sample had incomes below the poverty level as determined by federal approval for free or reduced price school lunches.

Participants in the cross-validation sample were 427 children from 21 classrooms in 16 schools, for whom measurements could be obtained for 10 or more children per classroom. The gender composition of the crossvalidation sample (50.3\% female) did not differ significantly from that of the exploratory sample $\left[\chi^{2}(1)=.05\right]$. Likewise, the ethnic composition of the cross-validation sample (37.1\% African American, 20.4\% Anglo, and $40.9 \%$ Latino) did not differ significantly from that of the exploratory sample $\left[\chi^{2}(3)=5.26, p=n s\right]$. The grade distribution for the cross-validation sample was $40.5 \%$ third graders and $59.5 \%$ sixth graders at the time of posttest. 
Seventy and eight-tenths percent of the cross-validation sample qualified for free school lunch, which was slightly higher than the rate for the exploratory sample $\left[\chi^{2}(1)=8.7, p<.05\right]$. Data from the cross-validation sample were collected one year after data collection from the exploratory sample.

\section{Measures}

Archival data on children's grade, gender, ethnicity, and free lunch status were gathered from school records and verified by teachers. Individual measures of behavior and beliefs were gathered from peers, teachers, classroom observations, and individual self-report. The following four measures were used as a basis for individual level and classroom level constructs.

\section{Peer Nomination Inventory}

Aggression, popularity, and rejection were assessed using the corresponding scales of the Peer Nomination Inventory (Eron, Walder, \& Lefkowitz, 1971). This procedure presents each child with a printed page displaying a list of all boys and girls in his or her classroom, with the names grouped by gender. The child is asked to cross off every name that fits the question asked by the assessor (e.g., "Who pushes and shoves other children?"). The administrator reads each statement and paces the children so that sufficient time is spent on each question. Nine questions tap aggression, three questions measure rejection, and two questions measure popularity. The child's score is the ratio of the number of nominations to the number of nominators, averaged across scale items. This measure has been used for over 30 years with demonstrated reliability and validity in several cultures (Eron \& Huesmann, 1986).

\section{Normative Beliefs Approving of Aggression (NOBAGS)}

The Normative Beliefs About Aggression Scale (Huesmann \& Guerra, 1997; Huesmann, Guerra, Miller, \& Zelli, 1992) is a 20-item self-report measure of children's beliefs about the appropriateness of physical and verbal aggression. The Retaliatory Beliefs Subscale (12 items) taps beliefs about the appropriateness of aggressive responses to provocation, and the General Beliefs Subscale ( 8 items) measures overall endorsement of aggressive responses. The retaliatory beliefs subscale has an internal consistency of .83 by Cronbach's alpha and one-year stability of $.34(p<.001)$ in this 
sample. The general beliefs subscale has an internal consistency of .81 and one-year stability of .33 in this sample. Previous research has demonstrated good retest reliability and has found significant cross-sectional and longitudinal correlations between this measure and measures of aggressive behavior (Huesmann \& Guerra, 1997).

\section{Child Behavior Checklist (CBCL)}

The CBCL (Achenbach, 1991) is a 119-item measure in which teachers rate each child on eight scales including (1) aggressive behavior, (2) anxiety/ depression, (3) attention problems, (4) delinquent behavior, (5) social problems, (6) somatic complaints, (7) thought problems, and (8) withdrawal. Each item is rated on a 3-point scale anchored by Never, Occasionally, and Often. The 39-item aggression scale was used in the present study. This scale had an internal consistency (Cronbach's alpha) of .98 in this sample.

\section{Observations of Student and Teacher Behavior}

We gathered observations of student and teacher behaviors using a method for real-time, multiple-entry observations on laptop computers (Repp, Harman, Felce, VanAcker, \& Karsh, 1989; Van Acker, Bush, Grant, \& Getty, 1991). As a part of the larger study, direct observations of student and teacher behaviors for all targeted at-risk students were conducted each year. Observation sessions were 20 minutes long at randomly selected structured and unstructured times during the school day to maximize the probability of gathering samples of low base-rate behaviors. The behavioral codes included information related to the instructional setting and structure, student task-related behavior, student compliance, social interaction, academic responding, and the nature of teacher feedback. We made use of a composite aggressive behavior scale, consisting of the summed occurrences of verbal and physical, initiated and retaliatory aggression against peers and teacher for each observation session. We also used individual behavioral codes for verbal and physical aggression and teacher responses of praise and reprimand in this investigation.

Prior to collecting observations, observers passed a criterion test on code definitions with $95 \%$ accuracy, and achieved an $85 \%$ overall percentage agreement with another observer on three consecutive sessions. No individual code fell below an $80 \%$ overall percentage agreement within a $\pm 2 \mathrm{sec}$ window. Reliability checks were conducted across codes throughout the 
data collection period on approximately $10 \%$ of the total sessions to avoid decay in reliabilities.

\section{Individual and Classroom-Level Constructs}

Using the four previously described instruments, we devised measures of individual normative beliefs and individual aggression, classroom descriptive norms, classroom injunctive norms, and classroom norm salience, as follows.

Individual normative beliefs were determined using the 12-item Retaliatory Beliefs Subscale of NOBAGS (Huesmann \& Guerra, 1997; Huesmann, Guerra, Miller, \& Zelli, 1992). Individual aggression was based on the child's score on the Aggression Scale of the Peer Nomination Inventory (Eron et al., 1971).

Prior to constructing measures of classroom norms, we conducted analyses to determine whether there was sufficient classroom clustering in the CBCL aggression and General Beliefs measures to warrant constructing aggregated measures (Ostroff, 1993). The intraclass correlations $\left(\rho_{i}\right.$, Hays, $1988)$ for both variables were significant $\left(\rho_{i}=.20\right.$ for CBCL Aggression, .07 for General Beliefs about Aggression, $p$ s $<.001)$. This indicated that there was sufficient within-classroom similarity in these measures to indicate the existence of a classroom norm, and to make aggregation of the measures at the classroom level reasonable.

Classroom descriptive norms were determined using the mean of classmates' CBCL aggression scores excluding the participant, in order to produce a measure that would not be influenced by the individual participant's score. Classroom injunctive norms were determined using the mean of classmates' scores on the General Beliefs Subscale of NOBAGS, also excluding the participant. We did not construct classmates' measures from the same instruments used for individual measures because there is withinclassroom linear dependency between the classmates' mean and individuals' scores on any variable $(r(n \bar{X}-x) /(n-1), x=-1.0)$.

Three measures of classroom norm salience were as follows: (1) Rejection of aggressive children among peers, calculated as the within-classroom correlations between CBCL aggression scores and peer-nominated rejection, (2) Popularity of aggressive children among peers, calculated as the within-classroom correlation between CBCL aggression scores and peernominated popularity, and (3) Teacher reprimand of aggressive behavior, which was the correlation between observations of aggressive behavior and teacher reprimand within each classroom.

Except for the baseline measure of aggression, measures for the cross- 
validation sample were identical to those for the exploratory sample. The cross-validation sample had not been administered peer nominations at pretest. Rather, a composite aggression measure was constructed from CBCL aggression scores and Teacher Predictions of Peer Nominations (Huesmann, Eron, Guerra, \& Crawshaw, 1994). The correlation between this measure and posttest peer nominated aggression was only slightly lower than that between pre- and posttest peer-nominated aggression.

\section{Procedure}

Exploratory sample measures of aggression and normative beliefs were collected in 1991 and 1993. Participants were administered the Normative Beliefs Scale and the Peer Nominations Inventory at their school desks. The measures were administered by an experimenter unfamiliar to the children. The classroom teacher was not in the room at the time of administration. Teachers also completed the full Teacher's Rating Form of the Child Behavior Checklist in 1991 and 1993. Behavioral observations were made on high-risk children with pretest levels of aggression above the median in the spring of 1993. In these analyses, we included peer nomination and self-report data on normative beliefs from 1991 and 1993, and teacher ratings and classroom observation data from 1993. We collected data from the cross-validation sample according to the same schedule, but one year later.

\section{RESULTS}

Descriptive statistics and intercorrelations of all variables for the exploratory sample may be found in Table I. Table II contains descriptive statistics and intercorrelations for the cross-validation sample. Measures in this study were taken from those in each classroom with permission to participate in the study. In 1991, this averaged $84 \%$ of the total number of students in the school. Two years later, attrition had reduced the percentage of participants to approximately $60 \%$ of the total number of students in each classroom. As we did not have permission to obtain measures from the remaining students, we could not test the representativeness of the sample with respect to our measures. Using data reported to the state, however, we could determine whether our sample came from the general school population with respect to reading scores and absenteeism rates, using single-sample $t$-tests. There was no difference between children included in our sample and other children in these classrooms on the Iowa 
Table I. Descriptive Statistics and Intercorrelations of Variables: Exploratory Sample: $n=614$

\begin{tabular}{|c|c|c|c|c|c|c|c|c|}
\hline Measure & Mean & $(S D)$ & 1 & 2 & 3 & 4 & 5 & 6 \\
\hline $\begin{array}{l}\text { 1. } \mathrm{PN}^{a} \text { Aggression } \\
\text { (Baseline) }\end{array}$ & .21 & $(.18)$ & - & & & & & \\
\hline 2. $\mathrm{PN}^{a}$ Aggrerssion & .22 & $(.17)$ & $.64^{c}$ & - & & & & \\
\hline $\begin{array}{l}\text { 3. Normative Beliefs } \\
\text { about Aggression } \\
\text { (Baseline) }\end{array}$ & 2.0 & $(.65)$ & $.16^{c}$ & $.11^{c}$ & - & & & \\
\hline $\begin{array}{l}\text { 4. Normative Beliefs } \\
\text { about Aggression }\end{array}$ & 2.2 & $(.68)$ & $.10^{b}$ & $.23^{c}$ & $.28^{b}$ & - & & \\
\hline $\begin{array}{l}\text { 5. Injunctive Norms } \\
\text { (Classmates } \\
\text { Normative Beliefs) }\end{array}$ & 1.6 & $(.24)$ & $.13^{c}$ & $.17^{c}$ & $.11^{c}$ & $.16^{c}$ & - & \\
\hline $\begin{array}{l}\text { 6. Descriptive Norms } \\
\text { (Classmates' } \\
\text { Aggression) }\end{array}$ & 7.7 & $(6.1)$ & $.12^{c}$ & .04 & .07 & -.00 & $.23^{c}$ & - \\
\hline
\end{tabular}

${ }^{a}$ Peer-nominated aggression.

${ }^{b} p<.05$.

${ }^{c} p<.01$.

Table II. Descriptive Statistics and Intercorrelations of Variables: Cross-Validation Sample: $n=427$

\begin{tabular}{|c|c|c|c|c|c|c|c|c|}
\hline Measure & Mean & $(S D)$ & 1 & 2 & 3 & 4 & 5 & 6 \\
\hline $\begin{array}{l}\text { 1. Aggression }{ }^{a} \\
\text { (Baseline) }\end{array}$ & 1.20 & (2.3) & - & & & & & \\
\hline 2. $\mathrm{PN}^{b}$ Aggression & .22 & (.19) & $.61^{d}$ & - & & & & \\
\hline $\begin{array}{l}\text { 3. Normative Beliefs } \\
\text { about Aggression } \\
\text { (Baseline) }\end{array}$ & 2.1 & $(.57)$ & .07 & $.13^{d}$ & 一 & & & \\
\hline $\begin{array}{l}\text { 4. Normative Beliefs } \\
\text { about Aggression }\end{array}$ & 2.1 & $(.71)$ & .08 & $.24^{d}$ & $.30^{d}$ & 一 & & \\
\hline $\begin{array}{l}\text { 5. Injunctive Norms } \\
\text { (Classmates } \\
\text { Normative Beliefs) }\end{array}$ & 1.5 & $(.26)$ & $.09^{c}$ & $.19^{d}$ & .04 & $.26^{d}$ & - & \\
\hline $\begin{array}{l}\text { 6. Descriptive Norms } \\
\text { (Classmates' } \\
\text { Aggression) }\end{array}$ & 6.6 & $(5.0)$ & $.13^{d}$ & .05 & .00 & .07 & $.31^{d}$ & 一 \\
\hline
\end{tabular}

${ }^{a}$ Composite teacher-rated aggression.

${ }^{b}$ Peer-nominated aggression.

${ }^{c} p<.05$.

${ }^{d} p<.01$. 
Test of Basic Skills reading scores $[t(456)=1.2, p=n s]$. Children in our sample were absent approximately one day less than children from the general school population $[t(456)=2.6, p<.01]$.

We also compared demographic characteristics and pretest measures of children in the exploratory sample and children not included in 1993 because of attrition or nonparticipation of teachers. There was no difference between the sample and nonparticipants by the gender composition of classrooms $\left[\chi^{2}(1)=.15, p=n s\right]$. As the smaller city had a lower attrition rate than the large city, proportionally more children in the small city were in the sample than children in the large city $\left[\chi^{2}(1)=58.87, p<.001\right]$. However, within location, there was no difference between the ethnic composition of the sample and nonrespondents $\left[\chi^{2}(4)=2.9, p=\mathrm{ns}\right.$, for large city; $\chi^{2}(4)=6.9, p=\mathrm{ns}$, for small city].

Independent-samples $t$-tests revealed no differences between the exploratory sample and nonparticipants on pretest peer-nominated aggression $(t=.41, p=\mathrm{ns})$ or pretest situational normative beliefs about aggression $(t=.71, p=n s)$. Based on this evidence and the absence of demographic differences, we concluded that the sample employed was sufficiently representative of all the students in the classrooms.

We tested Hypotheses 1 and 2 using path analysis through LISREL 8 (Joreskog \& Sorbom, 1993). These hypotheses related to the effects of descriptive norms (classmates' aggregated aggressive behavior) and injunctive norms (classmates' aggregated normative beliefs about aggression) and personal normative beliefs on change in individual aggressive behavior, and expected age differences in these processes.

\section{Hypothesis 1: Descriptive and Injunctive Classroom Norms and Aggression}

Hypothesis 1 stated that both descriptive and injunctive norms would be significant predictors of change in individual normative beliefs and aggressive behavior, controlling for earlier individual beliefs and aggressive behavior. Moreover, we expected that personal normative beliefs would be a mediator between the classroom descriptive and injunctive norms and aggressive behavior.

To test this hypothesis, we set all path coefficients between descriptive and injunctive classroom norms and change in normative beliefs and aggression at zero. This model was a poor fit to the data $\left[\chi^{2}(4)=21.75, p<\right.$ .001]. Next, we tested a model in which the parameters for descriptive and injunctive classroom norms were freed. Freeing four parameters resulted in a model with 0 degrees of freedom. Upon examining significance tests 
for the parameters involving both measures of classroom norms, we fixed the parameter linking descriptive norms to individual retaliatory beliefs at 0 , since it was not statistically significant. The resulting model was an excellent fit to the data $\left[\chi^{2}(1)=1.63, p=n s\right]$. Subtracting the $\chi^{2}$ statistic of the full $(d f=1)$ model from that of the reduced model $(d f=4)$ showed that the reduced model improved the fit to the data significantly $\left[\chi^{2}(3)=\right.$ 20.12, $p<.001]$. Contrary to our first hypothesis, neither the direct nor indirect effect of descriptive norms on change in aggression was significant. However, both the indirect and direct effects of injunctive norms were significant predictors of change in aggression $(\beta=.07, p<.01)$, for direct effect, $\beta y=.03, t(607)=3.71, p<.01$, for indirect effect of injunctive norms on aggression through individual normative beliefs). We also tested a model in which aggressive behavior predicted individual normative beliefs. This path coefficient was not significant, whereas the reverse path was. To arrive at a final model of the relation between classroom norms and individual normative beliefs and aggressive behavior, we deleted nonsignificant path parameters between individual normative beliefs at pretest and aggressive behavior at posttest, and between individual pretest aggressive behavior and posttest normative beliefs. The final model was also an excellent fit to the data $\left[\chi^{2}(4)=7.61, p=n s\right]$. It is shown in Figure 1 .

Because these data were taken from an intervention study, we tested the homogeneity of the model parameters between schools in the control condition and those in the treatment conditions. Finding the parameters to be homogeneous would allow us to use all of the data in the study. A path analysis that set the parameters linking descriptive and injunctive norms with change in aggression equal in control and intervention conditions was a reasonable, although not a perfect fit to the data $\left[\chi^{2}(6)=14.15\right.$, $p<.05$; probability of close fit $($ RMSEA $<.05)=.50]$. The RMSEA, or root mean squared error of approximation, is an index of the average degree of misfit of any parameter estimate in a covariance structure model. The probability of close fit greater than or equal to .5 indicates that the model is a reasonable fit to the data, even though the value of $\chi^{2}$ may be inflated because of model complexity, skewed distributions of variables, or other factors. The close fit of this multiple-group model to the data indicated that the parameters linking descriptive and injunctive classroom norms with individual aggression and normative beliefs were reasonably homogeneous across intervention and control conditions. Investigation of differences in parameters between control and intervention conditions showed that the effect of descriptive norms on individual normative beliefs was somewhat stronger, although still not significant, in the control condition.

We also tested the homogeneity of the parameters of the best fitting model across ethnicities and genders using multiple-group analysis through 


\section{Exploratory Sample $(n=614)$}

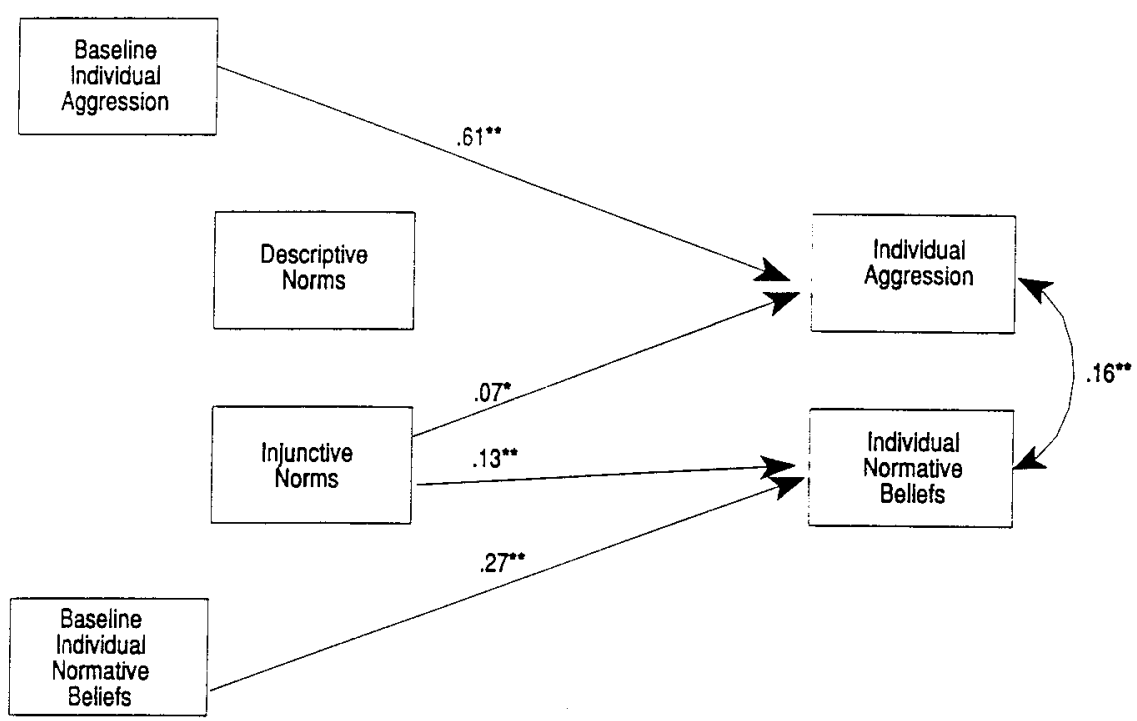

Fig. 1. Descriptive and injunctive norms and change in aggression and beliefs about aggression: Exploratory sample. Note: Only significant path coefficients are shown.

LISREL. The model fit equally well for children of different ethnicities $\left[\chi^{2}(14)=21.22, p=n s ;\right.$ probability of close fit $($ RMSEA $\left.<.05)=.91\right]$ and both genders $\left[\chi^{2}(7)=13.74, p=\right.$ ns; probability of close fit $($ RMSEA $<$ $.05)=.67]$.

Greater change in aggression might be expected for persons at higher baseline levels of aggression. It is also possible that the impact of environmental influences differs depending on individual levels of aggression. To determine whether or not there are differential effects of classroom norms by level of aggression, we tested the best fitting model for homogeneity across different levels of aggression by splitting the sample at the baseline median peer-nominated aggression score (.16), and conducting subgroup analysis through LISREL, as was done for other potential moderators of these effects. In this model, the paths between classmates' variables and individual variables were constrained to be equal across samples. The variance of peer-nominated aggression, and the paths representing change in aggression and normative beliefs, and the path between final individual normative beliefs and aggression, were allowed to vary between samples. This model was an excellent fit to the data $\left[\chi^{2}(9)=11.6, p=\mathrm{ns} ; p(\right.$ close 
fit $)=.92]$. There was greater stability of aggression in the low-aggression group $(\beta=.9)$, as compared to the high-aggression group $(\beta=.6)$ indicating, perhaps, greater magnitude of change in the high-aggression group. However, the relations between classroom norms and individual variables did not differ by level of baseline aggression.

\section{Hypothesis 2: Classroom Norms and Age}

Hypothesis 2 stated that age would moderate the effects of classroom norms on aggressive behavior. We predicted that in the earlier grades, descriptive norms would predict aggressive behavior that would predict, in turn, individual normative beliefs. In the older grades we expected that injunctive norms would predict individual normative beliefs that would predict, in turn, aggressive behavior.

We tested this hypothesis using multiple group analysis through LISREL-8, in order to determine whether there were significant parameter differences between older and younger children. We selected children in third and sixth grades at posttest for this analysis. Intercorrelations of variables by grade are shown in Table III. We tested the full model for homogeneity of the paths involving classroom norms across groups divided by these grade levels. In this analysis, the overall $\chi^{2}$ was significant $\left[\chi^{2}(7)=20.1, p<.01\right]$ and the model was not a close fit to the data (probability of close fit $\{$ RMSEA $<.05\}=.17$ ), indicating that there were differences by grade in the parameters linking descriptive and injunctive norms to change in aggression and normative beliefs.

The results of this model $\left[\chi^{2}(11)=14.7, p=n s\right]$, shown in Table IV, suggested that among third graders, injunctive norms predicted change in normative beliefs only, whereas among sixth graders, injunctive norms affected both normative beliefs and aggressive behavior.

Table III. Correlations Among Variables, By Grade: 3rd Grade, $n=168$ (Above Diagonal) 6th Grade, $n=248$ (Below Diagonal)

\begin{tabular}{|c|c|c|c|c|c|c|}
\hline & 1 & 2 & 3 & 4 & 5 & 6 \\
\hline 1. Aggression ${ }^{a}$ (Pre) & - & $.59^{c}$ & .17 & .16 & .34 & $.25^{c}$ \\
\hline 2. Aggression ${ }^{a}$ (Post) & $.60^{c}$ & - & .11 & $.16^{b}$ & $.17^{b}$ & .06 \\
\hline 3. Normative Beliefs (Pre) & $.18^{c}$ & $.14^{b}$ & - & .13 & $.25^{c}$ & -.02 \\
\hline 4. Normative Beliefs (Post) & .03 & $.27^{c}$ & $.33^{c}$ & - & -.04 & .04 \\
\hline 5. Descriptive Norms & .10 & .05 & .11 & .12 & - & .38 \\
\hline 6. Injunctive Norms & .10 & $.23^{c}$ & .08 & $.19^{c}$ & $.30^{c}$ & - \\
\hline
\end{tabular}

${ }^{a}$ Peer-nominated aggression.

${ }^{b} p<.05$.

${ }^{c} p<.01$. 
Table IV. Effects of Classmates' Aggressive Beliefs and Behavior: Standardized Covariance Structure Model Parameters and Significance Tests, by Grade and Sample

\begin{tabular}{|c|c|c|c|c|c|c|c|c|}
\hline \multirow[b]{6}{*}{ Predictor } & \multicolumn{8}{|c|}{ Sample } \\
\hline & \multicolumn{4}{|c|}{$\begin{array}{c}\text { Exploratory } \\
n=416(3 \text { rd and 6th only) }\end{array}$} & \multicolumn{4}{|c|}{$\begin{array}{c}\text { Cross-Validation } \\
n=427\end{array}$} \\
\hline & \multicolumn{4}{|c|}{ Time 2 Criterion } & \multicolumn{4}{|c|}{ Time 2 Criterion } \\
\hline & \multicolumn{2}{|c|}{ Behavior } & \multicolumn{2}{|c|}{ Beliefs } & \multicolumn{2}{|c|}{ Behavior } & \multicolumn{2}{|c|}{ Beliefs } \\
\hline & \multicolumn{2}{|c|}{ Grade } & \multicolumn{2}{|c|}{ Grade } & \multicolumn{2}{|c|}{ Grade } & \multicolumn{2}{|c|}{ Grade } \\
\hline & 3 & 6 & 3 & 6 & 3 & 6 & 3 & 6 \\
\hline $\begin{array}{l}\text { Time } 2 \\
\text { Beliefs }\end{array}$ & .05 & $.18^{c}$ & - & - & .02 & $.25^{c}$ & - & - \\
\hline $\begin{array}{l}\text { Individual } \\
\text { Behavior }\end{array}$ & $.52^{c}$ & $.57^{c}$ & .05 & -.04 & $.61^{c}$ & $.59^{c}$ & .06 & .01 \\
\hline $\begin{array}{l}\text { Individual } \\
\text { Beliefs }\end{array}$ & .01 & -.07 & $.14^{a}$ & $.32^{c}$ & -.05 & $.08^{c}$ & $.17^{c}$ & $.39^{c}$ \\
\hline $\begin{array}{r}\text { Classmates' } \\
\text { Behavior }\end{array}$ & -.06 & -.06 & -.03 & -.02 & -.06 & -.07 & .05 & -.04 \\
\hline $\begin{array}{l}\text { Classmates' } \\
\text { Beliefs }\end{array}$ & $.08^{c}$ & $.09^{c}$ & $.11^{c}$ & $.16^{c}$ & $.11^{c}$ & $.12^{c}$ & $.19^{c}$ & $.13^{c}$ \\
\hline
\end{tabular}

${ }^{a} p<.10$.

${ }^{b} p<.05$.

${ }^{c} p<.01$.

These findings were contrary to Hypothesis 2, which predicted effects for descriptive norms in lower grades. Descriptive norms did not have significant effects in either grade, but injunctive norms had effects on personal norms in third grade, and on personal norms and aggression in sixth grade.

\section{Hypothesis 3: Salience of Injunctive Norms in Classrooms}

We predicted that children in classrooms where both peers and teachers disapprove of aggressive behavior would show the smallest increase in aggression over time. Hypothesis 3 also stated that classrooms would vary in the extent to which they made injunctive norms about aggression salient to children in them. We operationalized salience using three classroomlevel measures: (1) the within-classroom correlation between CBCL aggression and peer-nominated popularity, (2) the within-classroom correlation between CBCL aggression and peer-nominated rejection, and (3) the within-classroom correlation between observed teacher reprimand and observed aggressive behavior. We tested the homogeneity of the distributions of within-classroom correlations using a $\chi^{2}$ test that is frequently used in 
meta-analysis (Rosenthal \& Rubin, 1982). Although the median correlations indicate that aggressive children are moderately unpopular and rejected among peers, there was enough variability among classrooms to suggest that all of the within-classroom correlations were not from the same population. Within-classroom correlations between aggression and peer rejection ranged from -.3 to +.9 , and correlations between aggression and peer popularity ranged from -.8 to +.7 . Within-classroom correlation between aggressive behavior and teacher reprimand ranged from -.5 to +.9 . The distribution of within-classroom correlations between peer rejection and aggression $\left[\chi^{2}(45)=76.2, p<.01\right]$ and the distribution of correlations between teacher reprimand and observed aggressive behavior $\left[\chi^{2}(45)=305.5, p<.01\right]$ were clearly heterogeneous. The distribution of correlations between peer popularity and aggression bordered on heterogeneity $\left[\chi^{2}(45)=59.8, p=.05\right]$.

Classrooms appeared to differ in the extent to which norms for aggressive behavior were made salient by peers and teachers. The apparent slope differences between classrooms suggested that we use hierarchical linear modeling as a test of Hypothesis 3. In our data, use of this approach was complicated because the sample size for teacher reprimand and observed aggression was substantially smaller than the sample for peer popularity, rejection and individual aggression. Including all measures in a single model would have reduced our sample size substantially, rendering it less representative of the population.

Moreover, methods for covariance structure modeling with hierarchically clustered data are not yet well developed (Sorbom, personal communication). Although Muthén (1994) has offered a multilevel covariance structure model, this method, as it existed at the time of this writing, would have required the same number of students in all classrooms, or would have required a separate measurement model for classrooms of each size.

We were able to construct partial tests of Hypothesis 3 using multilevel statistical models implemented through SAS PROC MIXED, in which individual aggression was modeled as a function of previous aggression, classroom-level popularity of aggression, rejection of aggression, and teacher contingent reprimand of aggression, specifying classroom as the "subject." The results showed that there was significant variance among classrooms in mean aggression $\left(\tau_{00}=.07, Z=2.75, p<.05\right)$. Moreover, the effect of classroom-level rejection of aggression was significant $[\beta=$ $-.55, t(40)=2.44, p<.05]$. Stronger positive association between classroom-level rejection of aggression was associated with decreased individual aggression, supporting Hypothesis 3. Neither the effect for classroom-level popularity of aggression $[\beta=-.26, t(40)=-1.39, \mathrm{~ns}]$ nor the effect for 
classroom-level reprimand of aggression $[\beta=-.26, t(40)<1$, ns $]$ reached significance.

The extent to which a classroom makes norms regarding aggression salient to students might be a result of the combination of peer and teacher behaviors toward aggression. For this reason, we also approached Hypothesis 3 using a cluster analytic strategy. We used nonhierarchical multivariate cluster analysis to determine whether types of classrooms could be derived from the three within-classroom correlations. We fit two-through eightcluster solutions using K-means clustering (Seber, 1984, p. 381). This method is analogous to a multivariate analysis of variance (MANOVA) in reverse. Whereas a MANOVA determines the variance in a canonical variate accounted for by known groups, K-means clustering attempts to find groups that maximize the ratio of between-cluster variance to withincluster variance, iteratively reassigning observations to clusters based on the distances of observations to the cluster centroids. A scree plot of the mean distances between data points and cluster centroids for different numbers of clusters suggested two possible stopping points in the cluster solution: one at four, and the other at eight clusters. Wishart (1982) gives a method for determining the optimal numbers of clusters in a hierarchical cluster solution. We adapted this for nonhierarchical clustering by treating each solution as a repeated measurement of the distance between an individual's data and his or her cluster centroid. We then conducted dependentsample $t$-tests of the distances between each solution and the solution representing the next lower number of clusters. Using this method, we determined that a four-cluster solution was optimal $[t(46)=4.06, p<.05$, for four- vs. three-cluster solutions; $t(46)=.25, p=\mathrm{ns}$, for five- vs. fourcluster solutions]. All three within-classroom correlations contributed significantly to the solution.

Table V shows the mean within-classroom correlations for each cluster.

Table V. Characteristics of Classroom Clusters: $n=48$ Classrooms

\begin{tabular}{lccc}
\hline \multicolumn{1}{c}{$\begin{array}{c}\text { Cluster } \\
(n \text { of Classrooms) }\end{array}$} & $\begin{array}{c}\text { Peer-Nominated } \\
\text { Popularity } \\
\text { of Aggressive } \\
\text { Children }\end{array}$ & $\begin{array}{c}\text { Peer-Nominated } \\
\text { Rejection } \\
\text { of Aggressive } \\
\text { Children }\end{array}$ & $\begin{array}{c}\text { Teacher } \\
\text { Reprimand of } \\
\text { Aggressive } \\
\text { Behavior }\end{array}$ \\
\hline A. Peer and Teacher $(9)$ & $-.61(.12)_{\mathrm{a}}$ & $.78(.12)_{\mathrm{e}}$ & $.63(.25)_{\mathrm{g}}$ \\
B. Teacher Only (16) & $-.14(.20)_{\mathrm{b}}$ & $.41(.19)_{\mathrm{f}}$ & $.57(.25)_{\mathrm{g}}$ \\
C. Peer Only (20) & $-.32(.18)_{\mathrm{c}}$ & $.46(.23)_{\mathrm{f}}$ & $-.05(.20)_{\mathrm{h}}$ \\
D. Neither (3) & $.51(.23)_{\mathrm{d}}$ & $.33(.53)_{\mathrm{f}}$ & $-.04(.39)_{\mathrm{h}}$ \\
\hline
\end{tabular}

${ }^{a}$ Standard deviations of coefficients are in parentheses. Mean coefficients with different subscripts within columns are significantly different by Tukey HSD multiple comparisons $(p<.01)$. 
These are also displayed graphically in Figure 2. All four clusters differed significantly from each other in the popularity of aggressive children, according to protected $t$-tests. Aggressive children were most popular among their peers in cluster D classrooms, and least popular in cluster A classrooms. Aggressive children in cluster A classrooms were also more likely than those in the other clusters to be rejected by their peers. Children behaving aggressively in class were more likely to be reprimanded in cluster $\mathrm{A}$ and $\mathrm{B}$ classrooms than in clusters $\mathrm{C}$ and D classrooms. Accordingly, we named these clusters after those who in the classroom (peers or teachers) discouraged aggressive behavior: Peers and Teacher (A), Teacher only (B), Peers only (C), or Neither (D).

Demographic comparisons revealed that classroom clusters did not differ in the number of students in each classroom $[F(3,44)=1.96, p=n s]$. They also did not differ in their average pretest peer-nominated aggression means $[F(3,44)=1.06, p=n s]$. Fourth graders were more likely to be in Cluster A (Peer and Teacher) classrooms than were third or sixth graders $\left[\chi^{2}(6)=65.7, p<.001\right]$. Anglo children were more likely to be in Cluster $\mathrm{C}$ (Peer) classrooms than were children of other ethnic groups $\left[\chi^{2}(9)=\right.$ $45.9, p<.001$ ], and children in the smaller city were also more likely to be in Cluster $\mathrm{C}$ (Peer) classrooms than their counterparts in the larger urban

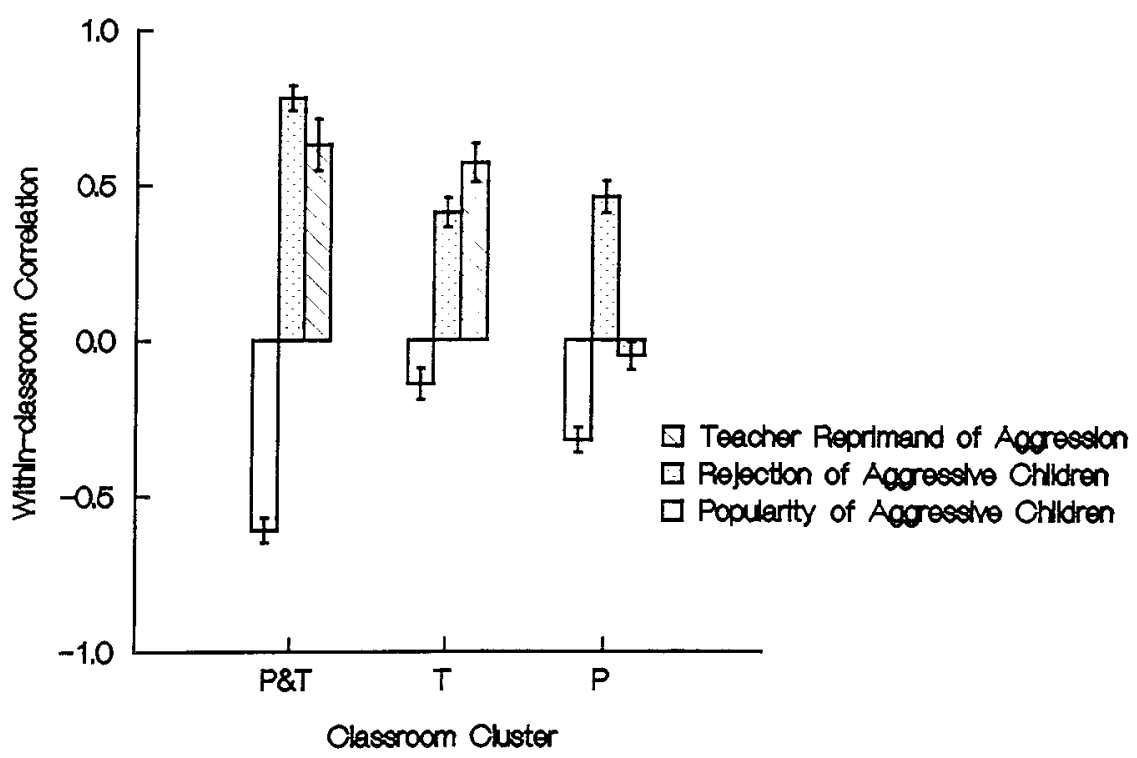

Fig. 2. Salience measures by clasroom cluster. Note: P: peer only classrooms; T: teacher only clasrooms; P\&T: peer and teacher classrooms. 
area $\left[\chi^{2}(3)=27.5, p<.001\right]$. Logistic regression of Cluster C membership $(1,0)$ on ethnicity and location found that the ethnic differences in Cluster $\mathrm{C}$ composition disappeared $\left[\chi^{2}(1)=.03\right.$, for African American and 2.23 for Hispanic, $p \mathrm{~s}=\mathrm{ns}]$, but location differences remained significant $\left[\chi^{2}(2)\right.$ $=9.06, p<.01]$. Because of small numbers of "neither peer nor teacher" classrooms $(n=3)$, and the fact that one of these classrooms was a special education classroom, we dropped this cluster from subsequent analyses.

We conducted an analysis of covariance (ANCOVA) relating 1993 peer-nominated aggression to 1991 peer-nominated aggression, gender, ethnicity, and classroom cluster in the model. The overall effect of classroom cluster was significant $[F(2,634)=4.21, p<.05]$. Figure 3 shows change in aggression by classroom cluster for both exploratory and cross-validation samples. Post hoc contrasts revealed that children in "peer and teacher" classrooms differed from those in the other clusters.

\section{Cross-Validation}

To determine the likelihood that these findings would generalize across samples, we tested our LISREL model and the analyses involving salience with the cross-validation sample $(n=427)$ described above.

The general model for Hypothesis 1 fit the cross-validation sample data well $\left[\chi^{2}(2)=1.8, p=n s\right]$. As had been the case with the exploratory sample, personal norms mediated the effect of injunctive norms, and descriptive norms had no significant effect on change in aggression.

The age differences found in the exploratory sample were also found in the cross-validation sample. A LISREL model identical to the final model for age differences in the exploratory analyses fit the cross-validation sample well $\left[\chi^{2}(11)=18.59, p=\mathrm{ns}\right]$.

For the cross-validation sample, we constructed classroom clusters similar to those in the initial sample using median splits of the classroomlevel salience correlations. This resulted in 112 students in peer and teacher classrooms, 73 in teacher-only classrooms, and 94 in peer-only classrooms. ANCOVA of posttest peer-nominated aggression on classroom cluster with pretest aggression as a covariate showed a significant effect for classroom cluster $[F(2,276)=8.82, p<.001]$. As in the exploratory sample, the smallest positive change in aggression was in the peer and teacher classrooms.

In the cross-validation sample, norm salience differed by classroom cluster $[F(2,183)=16.4, p<.001]$. As in the exploratory sample, peer and teacher classrooms had the strongest salience of injunctive norms against aggression. 
$\frac{1}{0}$
$\frac{8}{00}$
0
$\frac{5}{0}$
$\frac{0}{0}$
$\frac{0}{00}$
$\frac{1}{0}$
0
0
0
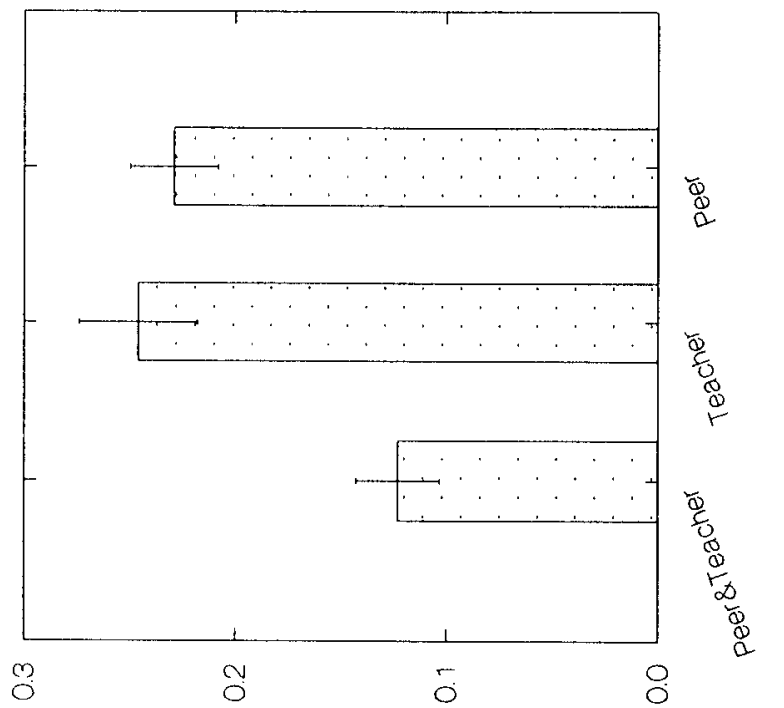

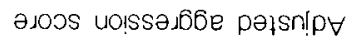
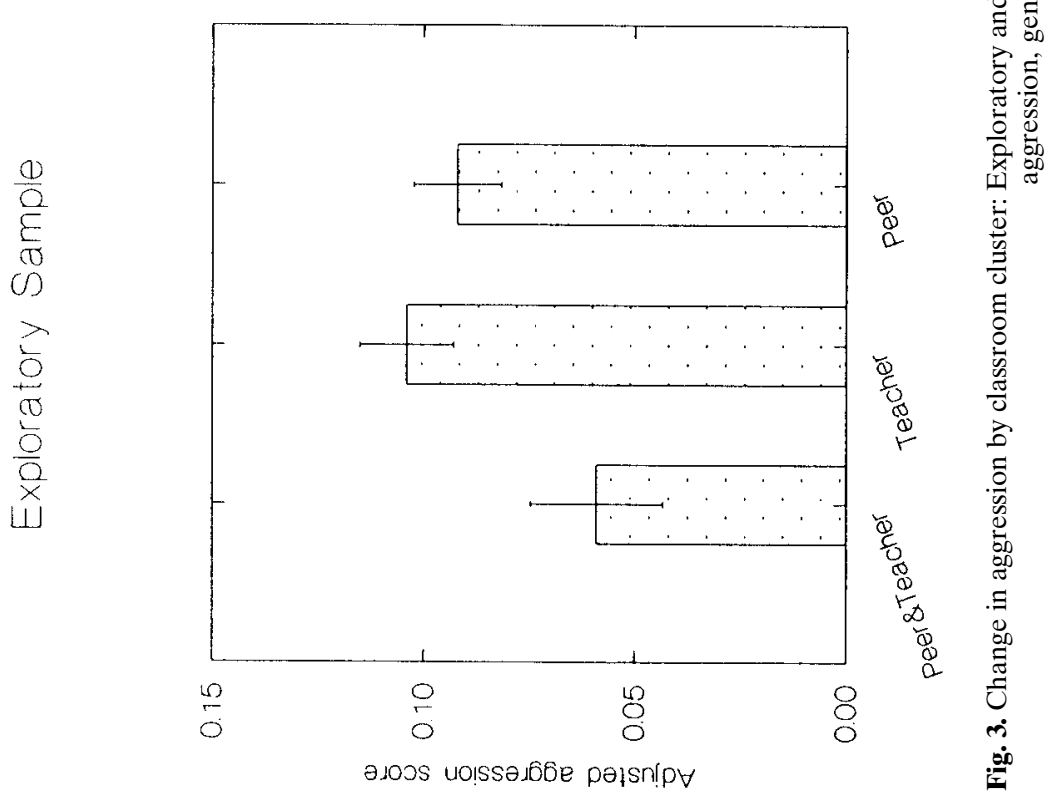
Henry et al.

\section{DISCUSSION}

These findings present a complex picture of normative influences in classrooms. Contrary to our predictions, descriptive classroom norms had no effect, either direct or indirect, on aggressive behavior. Injunctive norms, however, predicted change in aggression directly, and through personal norms (general normative beliefs). These results were homogeneous across genders and ethnicities and levels of initial aggression, but differed slightly by children's grade level. Injunctive norms had direct effects on aggressive behavior only among sixth graders, and individual aggression predicted personal norms only among third graders. Among both third and sixth graders, injunctive norms predicted personal norms.

We found that classrooms varied with respect to student and teacher measures of norm salience. Students in classrooms where peers and teachers discouraged aggression were less likely to show increased aggression over time than were children in other types of classrooms.

These findings generalized across two samples. Injunctive norms appeared to influence aggressive behavior by changing personal normative beliefs about aggression. Classrooms in which both peers and teachers discouraged aggression produced decreased aggression in the exploratory sample, and smaller increases in aggression in the cross-validation sample.

The age differences in normative influence patterns are consistent with previous research (Huesmann \& Guerra, 1997). We found that the stability of normative beliefs is greater in later than in earlier grades, which suggests that the early school years are a formative period for children's normative beliefs about aggression. During this time, children may form their beliefs about the appropriateness of aggression by conforming their beliefs to their behavior, and by adopting the beliefs of their peers. By sixth grade, their personal beliefs become important factors that, along with the normative climate of the setting, influence behavior.

Numerous interventions rely on modeling to change aggressive or inappropriate behavior (Clark, Beck, Sloane, \& Goldsmith, 1993; Kendall \& Braswell, 1986; Larson, 1992). This investigation suggests that children do not merely imitate the behavior of their classmates, but that behavioral choices are mediated by beliefs about the morality of aggressive behavior. These beliefs, in turn, are influenced by the moral climate of the classroom regarding aggressive behavior, rather than by the observed behavior of classmates. Further, when classmates and the teacher make salient injunctions against aggressive behavior, aggression diminishes.

It has been suggested that, just as involvement in delinquent peer groups promotes delinquent behavior, grouping aggressive children to- 
gether may promote increased aggressive behavior (Eargle, Guerra, \& Tolan, 1994; Sinclair, Pettit, Harrist, \& Dodge, 1994). This investigation found no evidence for such effects. The descriptive norms of the classroom (defined as the mean level of aggression of other children in the classroom) had no effect on either the personal norms or the aggressive behavior of individuals. Neither was there any indication that injunctive norms covaried with descriptive norms, as might have been expected.

We found that aggressive behavior increased least in classrooms in which both peers and teachers discouraged aggressive behavior. About $40 \%$ of the students in the exploratory sample were in classrooms in which peers, but not teachers, discouraged aggressive behavior. This suggests the possibility that teachers who increase the consistency of their behavioral feedback might find their efforts strengthened by the existence of injunctive norms among their students.

These findings offer insight into the ways in which interventions to reduce aggressive behavior may succeed. They suggest the possibility that efforts directed at changing personal normative beliefs, such as social responsibility curricula (e.g., Guerra \& Pannizzon, 1993), might affect behavior through two channels: (1) through changing the personal norms of students; and (2) as personal norms change, classroom injunctive norms may change and act to change the personal norms of other students. Time and consistency in applying interventions would be necessary for such change efforts to be effective.

Students appear to exert influence to reduce aggressive behavior in classrooms in which the teacher gives consistent behavioral feedback. Teachers who work on increasing the consistency of behavioral feedback might find that their efforts are enhanced by injunctive norms among their students. Interventions to help teachers learn to give appropriate, contingent, behavioral, as well as academic feedback might be effective in reducing aggressive behavior.

This study is limited primarily by the types of measures used. With the exception of our teacher-contingent reprimand measure, our measures of classroom characteristics were not designed for system-level measurement, but were constructed from available individual measures. Future research could use instruments designed to measure characteristics of the system, such as those used in Sasaki's (1979) studies of normative influences among Japanese work groups. There is also the possibility that accounting for classroom-level clustering in our data through greater use of multilevel statistical models might have produced somewhat different results. As described above, we partially tested Hypothesis 3 using a multilevel modeling approach, and found effects not inconsistent with those reported for the cluster-analytic approach. Multilevel tests of other hypotheses await the 
maturity of methods for multilevel models with multiple dependent variables and multilevel path analysis (cf., Muthén, 1994).

The effects found in these studies, though modest and suggestive, are consistent across samples and theoretically meaningful. Although we provide evidence that classroom injunctive norms affect aggressive beliefs and behavior, further research is needed on the ways in which descriptive and injunctive classroom norms develop, on the interaction of classroom norms and other higher-level influences, such as friendship groups and neighborhood contexts, and on the ways in which interventions can change classroom norms.

\section{REFERENCES}

Achenbach, T. M. (1991). Manual for the Child Behavior Checklist/4-18 and 1991 Profile. Burlington: University of Vermont Department of Psychiatry.

Bandura, A. (1986). Social foundations of thought and action: A social cognitive theory. Englewood Cliffs, NJ: Prentice-Hall.

Barker, R. G. (1968). Ecological psychology: Concepts and methods for studying the environment of human behavior. Stanford, CA: Stanford University Press.

Cialdini, R. B., Kallgren, C. A., \& Reno, R. R. (1991). A focus theory of normative conduct. Advances in Experimental Social Psychology, 24, 201-234.

Clark, E., Beck, D., Sloane, H., \& Goldsmith, D. (1993). Self-modeling with preschoolers: Is it different? School Psychology International, 14, 83-89.

Crick, N. R., \& Dodge, K. A. (1994). A review and reformulation of social informationprocessing mechanisms in children's social adjustment. Psychological Bulletin, 115, 74-101.

Deutsch, M., \& Gerard, H. B. (1955). A study of normative and informational social influences on individual judgement. Journal of Abnormal and Social Psychology, 51, 629-636.

Dodge, K. A. (1986). A social information-processing model of social competence in children. In M. Perlmutter (Ed.), Minnesota Symposium on Child Psychology (Vol. 18, pp. 77-125). Hillsdale, NJ: Lawrence Erlbaum.

Eargle, A. E., Guerra, N. G., \& Tolan, P. H. (1994). Preventing aggression in inner-city children: Small group training to change cognitions, social skills, and behavior. Journal of Child and Adolescent Group Therapy, 4, 229-242.

Eron, L. D., \& Huesmann, L. R. (1987). The stability of aggressive behavior in cross-national comparison. In C. Kagitcibasi (Ed.), Growth and progress in cross-cultural psychology (pp. 207-217). Berwyn, PA: Swets North America.

Eron, L. D., Walder, L. O., \& Lefkowitz, M. M. (1971). The learning of aggression in children. Boston, MA: Little-Brown.

Grusec, J. E. (1972). Demand characteristics of the modeling experiment: Altruism as a function of age and aggression. Journal of Personality and Social Psychology, 22, 139-148.

Guerra, N. G., Eron, L. D., Huesmann, L. R., Tolan, P. H., \& Van Acker, R. (1995). A cognitive/ecological approach to the prevention and mitigation of violence and aggression in inner-city youth. In K. Bjorkquist \& D. P. Fry (Eds.), Styles of conflict resolution: Models and applications from around the world (pp. 199-213). New York: Academic Press.

Guerra, N. G., Huesmann, L. R., \& Hanish L. (1995). The role of normative beliefs in children's social behavior. In N. Eisenberg (Ed.), Review of personality and social psychology, development and social psychology: The interface (pp. 140-158). Beverley Hills, CA: Sage.

Guerra, N. G., \& Pannizzon, A. (1993). Yes I can: Social responsibility training. Chicago, IL: Metropolitan Area Child Study. 
Guerra, N. G., \& Slaby, R. G. (1990). Cognitive mediators of aggression in adolescent offenders: II. Intervention. Developmental Psychology, 26, 269-277.

Hays, W. L. (1988). Statistics (4th ed.). New York: Holt, Reinhardt \& Winston.

Henry, D. B. (1995, March). Settings and individual behavior in complex interaction. Colloquium presentation, Department of psychology, University of Illinois at Chicago.

Huesmann, L. R. (1988). An information processing model for the development of aggression. Aggressive Behavior, 14, 13-24.

Huesmann, L. R., \& Guerra, N. G. (1997). Children's normative beliefs about aggression and aggressive behavior. Journal of Personality and Social Psychology, 72, 408-419.

Huesmann, L. R., Eron, L. D., Guerra, N. G., \& Crawshaw, V. B. (1994). Measuring children's aggression with teachers' predictions of peer nominations. Psychological Assessment, 6, 329-336.

Huesmann, L. R., Guerra, N. G., Zelli, A., \& Miller, L. (1992). Differing normative beliefs about aggression for boys and girls. In K. Bjorkqvist \& P. Niemela (Eds.), Of mice and women: Aspects of female aggression. Orlando, FL: Academic Press.

Huesmann, L. R., Guerra, N. G., Miller, L., \& Zelli, A. (1992). The role of social norms in the development of aggression. In H. Zumkley \& A. Fraczek (Eds.), Socialization and aggression. New York: Springer-Verlag.

Joreskog, K., \& Sorbom, D. (1993). Lisrel 8. Chicago, IL: Scientific Software.

Kendall, P., \& Braswell, L. (1986). Medical applications of cognitive-behavioral interventions with children. Journal of Developmental and Behavioral Pediatrics, 7, 257-264.

Larson, J. D. (1992). Anger and aggression management techniques through the Think First curriculum. Journal of Offender Rehabilitation, 18, 101-117.

Levine J. M. (1983). Social comparison and education. In Levine, J. M. \& Wang, M. C. (Eds.), Teacher and student perception: Implications for learning. Hillsdale, NJ: Lawrence Erlbaum Associates.

Metropolitan Area Child Study. (1992). Psychometrics of Measures, Technical report.

Muthén, B. (1994). Latent variable modeling of longitudinal and multilevel data. Invited paper for the annual meeting of the American Sociological Association, Section on Methodology, Showcase Session.

Ostroff, C. (1993). Comparing correlations based on individual-level and aggregated data. Journal of Applied Psychology 78, 569-582.

Repp, A. C., Karsh, K. G., VanAcker, R., Felce, D., \& Harman, M. (1989). A computerbased system for collecting and analyzing observational data. Journal of Special Education Technology, 9, 207-217.

Rosenthal, R., \& Rubin, D. (1982). Comparing effect sizes of independent studies. Psychological Bulletin, 92, 500-504.

Sasaki, K. (1979). Present status of research on group norms in Japan. American Journal of Community Psychology, 7, 147-158.

Seber, G. A. F. (1984). Multivariate observations. New York: John Wiley \& Sons.

Sinclair, J. J., Pettit, G. S., Harrist, A. W., \& Dodge, K. A. (1994). Encounters with aggressive peers in early childhood: Frequency, age differences, and correlates of risk for behaviour problems. International Journal of Behavioral Development, 17, 675-696.

Slaby, R. G., \& Guerra, N. G. (1988). Cognitive mediators of aggression in adolescent offenders: 1: Assessment. Developmental Psychology, 24, 580-588.

VanAcker, R., Bush, J., Grant, S. H., \& Getty, J. E. (1992). A software package for the intermittent time sampling of behavior. Chicago: Stoelting.

Wishart, D. (1982). Supplement, CLUSTAN User manual, Third Edition. Edinburgh, Scotland: Program Library Unit, Edinburgh University. 